\title{
La Mirada del Turista
}

\section{John Urry}

\section{Por qué el turismo es importante}

\begin{abstract}
La clínica fue probablemente el primer intento de ordenar una ciencia sobre el ejercicio y las decisiones de la contemplación ...la contemplación médica también fue organizada de una nueva forma. Primero, ya no se trataba de la contemplación de cualquier observador, sino de la de un doctor con el apoyo y la justificación de su institución... Más aun, era la contemplación que no estaba restringida por la estrecha rejilla de una estructura ... sino que podía y debía asir los colores, las variaciones, las pequeñas anomalias ... (Foucault, 1976: 89)
\end{abstract}

El tema de este artículo pareciera no tener nada en absoluto que ver con el mundo serio de la medicina y con la contemplación médica que preocupa a Foucault. Este es un libro sobre el placer, sobre las vacaciones, el turismo y los viajes, sobre cómo y por qué por cortos períodos de tiempo la gente deja sus lugares normales de trabajo y residencia. Es sobre el consumo de bienes y servicios que son de alguna manera innecesarios. Son consumidos por que supuestamente generan experiencias de placer que son distintas de las que típicamente enfrentamos en la vida cotidiana. $Y, \sin$ embargo, por lo menos parte de esa experiencia es de contemplar o examinar un grupo de esce- nas diferentes, de paisajes naturales o citadinos que salen de lo ordinario. Cuando 'nos vamos' vemos el entorno con interés y curiosidad. Nos habla de maneras que apreciamos, o al menos anticipamos que eso es lo que hará. En otras palabras, contemplamos aquello a lo que nos enfrentamos. Y esta contemplación está tan organizada y sistematizada socialmente como está la contemplación de un médico. Por supuesto es de diferente orden ya que no está confinada a profesionales 'con el soporte y la justificación de una institución'. Pero, aun en la producción de placer 'innecesario', hay, de hecho, muchos profesionales expertos que ayudan a construir y desarrollar nuestra contemplación como turistas.

Este artículo entonces habla sobre cómo en diferentes sociedades y, especialmente dentro de diferentes grupos sociales, en diversos períodos históricos la contemplación del turista ha cambiado y desarrollado. Analizaré los procesos por los cuales esta mirada se construye y refuerza y consideraré quién o qué las autoriza, cuáles son sus consecuencias para los 'lugares' que son su objeto y cómo se interrelaciona con una variedad de otras prácticas sociales.

No existe una única contemplación del turista como tal. Varia según la sociedad, por grupo social y por período histórico. Estas con- 
templaciones son construidas por medio de las diferencias. Con esto quiero decir no solamente que no hay una experiencia universal verdadera para todos los turistas en todos los tiempos. Más bien, la contemplación en cualquier período histórico se construye en relación a su opuesto, a formas no turísticas de experiencia y conciencia social. Lo que constituye la contemplación especifica de un turista depende de con qué se le constrasta; cuáles son en realidad las formas de experiencias no turísticas. La contemplación presupone por lo tanto un sistema de actividades y señas sociales que ubican las prácticas turísticas particulares, no en términos de algunas características intrínsecas, sino a través de los contrastes implicados en las prácticas sociales no turísticas, particularmente aquellas basadas en el hogar y el trabajo remunerado.

El turismo, la producción de vacaciones y los viajes son fenómenos sociales más significativos de lo que los comentaristas han considerado. De cara a esto no podría haber un tema más trivial para un libro. $Y$ visto que los científicos sociales han tenido bastantes dificultades para explicar temas de más peso, como el trabajo y la política, se podría pensar que tendrían grandes dificultades para discurrir por fenómenos más triviales como la producción de vacaciones. Sin embargo, hay paralelos interesantes con el estudio de la desviación. Esto implica la investigación de las prácticas bizarras e idiosincráticas que son definidas como desviadas en algunas sociedades, pero no necesariamente en otras. La asunción es que la investigación de lo desviado puede revelar aspectos interesantes y significativos de las sociedades 'normales'. Solo entender por qué varias actividades son tratadas como desviadas puede iluminar cómo diferentes sociedades operan de manera más generalizada.

Este artículo está basado en la noción de que un análisis similar puede ser aplicado al turismo. Estas prácticas involucran la noción de 'alejamiento', de un romper con las rutinas establecidas y con las prácticas de la vida de todos los días, permitiendo que nuestros sentidos se involucren con un juego de estímulos que contrastan con lo cotidiano y lo mundano. Al considerar los objetos típicos de la contemplación turística uno puede usarlos para enten- der los elementos de la sociedad en su conjunto contra los que se son constrastados. En otras palabras, el considerar cómo los grupos sociales construyen su contemplación turística es una buena manera de percibir qué es lo que está ocurriendo con una 'sociedad normal'. Podemos usar el hecho de la diferencia para interrogar a los normales por medio de la investigación de las formas típicas de turismo. Así, antes que ser un tema trivial, el turismo es significativo por su habilidad de revelar aspectos de las prácticas normales que pudieran de otra manera permanecer en la oscuridad. Desplegar los entretelones del mundo social frecuentemente requiere el uso de metodologías contra intuitivas y sorpresivas; como en el caso de la investigación de las 'alejamientos' involucrados en la mirada del turista.

Aunque he insistido en la variación histórica y sociológica de esta contemplación, hay unas características mínimas de la práctica social que son descritas convenientemente como 'turismo'. Ahora las expongo para establecer una base para los análisis históricos, sociológicos y globales que desarrollo más adelante.

1.- El turismo es una actividad de ocio que presupone su opuesto, a saber el trabajo regulado y organizado. Se trata de una manifestación de cómo el trabajo y el ocio están organizados como esferas separadas y reguladas de la práctica social en las sociedades 'modernas'. En realidad, actuar como un turista es una de las características definitorias de ser 'moderno' y esta ligado a grandes cambios en el trabajo remunerado. Esto ha devenido en una organización en lugares específicos y acontece por períodos regularizados.

2.- Las relaciones de los turistas surgen de un movimiento de personas a, y la permanencia de ellas en varios destinos. Esto necesariamente involucra algún movimiento en el espacio, estos son los viajes, y períodos de permanencia en un nuevo lugar o lugares.

3.- El viaje y la estadía son también a, y dentro, de locaciones fuera de los lugares normales de residencia y de trabajo. Los periodos de residencia en otro lugar son de naturaleza breve $y$ 
temporal. Hay una clara intención de regresar a 'casa' dentro de un lapso relativamente corto.

4.- Los lugares contemplados lo son no por razones directamente relacionadas con el trabajo remunerado y normalmente ofrecen algunos rasgos contrastantes con el trabajo (sea este remunerado o no).

5.- Una parte importante de la población de las sociedades modernas se involucra en estas prácticas turísticas; se proveen nuevas formas socializadas para satisfacer el carácter masivo de la contemplación de los turistas (en oposición al carácter individual del 'viaje').

6.- Los lugares a ser contemplados son elegidos debido a un proceso de anticipación, especialmente debida a las ilusiones y las fantasías sobre placer intenso, sea este a una escala distinta o por que se involucran sentidos diferentes de los que por costumbre utilizamos. Esta anticipación es construída y se sostiene por medio de una variedad de prácticas no turísticas, como películas, TV, literatura, revistas, discos y videos, que construyen y refuerzan esta contemplación.

7.- La mirada del turista esta dirigida a las características del paisaje rural y urbano que lo separa de la experiencia cotidiana. Estos aspectos son vistos por que son considerados, de alguna manera, fuera de lo común. El ver estos lugares turísticos frecuentemente implica diferentes formas de amoldamiento social, con una mayor sesibilización hacia elementos visuales del paisaje rural y urbano que aquel encontrado en la vida diaria. La gente se entretiene en esta contemplación que normalmente luego es visualmente objetivizada o capturada en fotografías, postales, películas, modelos y otros. Ello permite que la contemplación pueda ser reproducida o recapturada de manera continua.

8.- La mirada se construye por medio de signos, y el turismo implica la recolección de estos signos. Cuando el turista ve dos personas besándose en París lo que captura en la contemplación es el 'París romántico atemporal'. Cuando un pequeño poblado de Inglaterra es visto, lo que se contempla son las 'verdaderas tradiciones Inglesas'. Como Culler arguye: 'el turista está interesado en todo como un signo por si mismo ... Por todo el mundo los ejércitos desconocidos de la semiótica, los turistas, están movilizándose para descubrir las señales de lo Francés, el típico comportamiento italiano, las escenas orientales ejemplares, las típicas vías rápidas norteamericanas, los tradicionales pubs ingleses' (1981: 127).

9.- Surge una cantidad de profesionales del turismo que pretende reproducir siempre nuevos objetos de mirada turística. Estos objetos están ubicados en una jerarquía compleja y cambiante. Existe una dependencia de la interrelación entre, de un lado, la competencia entre los intereses involucrados en el aprovisionamiento de dichos objetos $y$, de otro lado, los cambios de gusto debidos a clases, sexo y edades de la población potencial de visitantes.

En este artículo considero el desarrollo de, y las transformaciones históricas en, la contemplación del turista. Principalmente hago un seguimiento de tales cambios en los últimos dos siglos; esto es, en el período en que el turismo masivo se ha difundido por casi toda Europa, Estados Unidos y va incrementando en otras partes del mundo. Ser un turista es una de las características de la experiencia 'moderna'. No 'irse' es como no poseer un auto o una bonita casa. Se ha convertido en un símbolo de status en las sociedades modernas y también es considerado necesario para la buena salud (ver Feifer, 1985: 224).

Esto no es para sugerir que no existía el viaje organizado en las sociedades pre modernas, pero era algo reservado a las élites (ver Towner, 1988). En la Roma imperial, por ejemplo, existía un patrón bastante amplio de viaje por placer y cultura para la élite. Se desarrolló una infraestructura para viajes, en parte permitida por dos siglos de paz. Se podía viajar desde el Muro de Adriano hasta el Eufrates sin cruzar una sola frontera hóstil (Feifer, 1985: cap.1). Seneca decái que esto permitía que los habitantes de las ciudades buscarán siempre nuevas sensaciones y placeres. 'Los hombres [sic] viajan mucho a diferentes tipos de lugares buscando diferentes distracciones por que son volubles, están cansados de la vida suave, y 
siempre están en busca de algo que los elude', dijo ( citado por Feifer, 1985: 9).

En los siglos XIII y XIV los peregrinajes se habían convertido en un fenómeno muy difundido 'practicable y sistematizado, servido por una creciente industria de redes de hospicios caritativos y guias de indulgencias de producción masiva' (Feifer, 1985: 29; Eade y Sallnow, 1991). Estos peregrinajes a menudo incluian una combinación de devoción religiosa y cultura y placer. Por el siglo quince habían recorridos organizados de Venecia a la Tierra Santa.

El Gran Recorrido se había establecido con solidez hacia el fin del siglo diecisiete para los hijos de la aristocracia y de los señores ricos y, llegado el siglo dieciocho para los hijos de la clase media profesional. A lo largo de este tiempo, entre 1600 y 1800 , los tratados sobre viajes pasaron de un énfasis escolástico sobre el turismo como una oportunidad del discurso, al viaje como la observación de primera vista. Hubo una visualización de la experiencia de viajar, o el desarrollo de la 'contemplación', ayudado y asistido por el incremento de guías que promovían nuevas maneras de ver ( ver Adler, 1989). El carácter mismo del viaje tomó otro curso, del temprano 'Gran Recorrido clásico', basado en la observación emocionalmente neutral y el registro de galerias, museos y artefactos de gran cultura, al 'Gran Recorrido romántico' del siglo diecinueve que vió emerger el 'turismo escénico' y una experiencia mucho más privada y apasionada de la belleza y lo sublime (ver Towner, 1985). También es importante anotar como se espera que el viaje tuviera un papel clave en la educación cognitiva y perceptual de la clase alta inglesa (ver Dent, 1975).

El siglo XVIII también vió el desarrollo de una considerable infraestructura turística en la forma de balnearios en toda Europa (Thompson, 1981: 11-12). Myercough indica que 'todo el aparato de la vida en balnearios con sus bailes, sus paseos, bibliotecas, maestros de ceremonias estaba diseñado para proveer una experiencia urbana concentrada de socialización frenética a la dispersa élite rural' (1974: 5). Siempre ha habido periodos en los que la masa de la población se ha involucrado en el juego y la recreación. En el campo el trabajo y el juego estaban particularmente entramados en el caso de las ferias. La mayoría de los pueblos y villorrios en Inglaterra tenían por lo menos una feria al año y muchos tenían más. La gente frecuentemente viajaba distancias considerables y las ferias siempre involucraban una combinación de negocios y placer normalmente centrados en torno a la taberna. Por el siglo dieciocho la casa pública se había convertido en un gran centro de vida pública en la comunidad, proveyendo luz, calor, implementación culinaria, muebles, noticias, operaciones bancarias y facilidades de viaje, entretenimiento y socialización (ver Harrison, 1971; Clark, 1983).

Pero antes del siglo XIX muy poca gente fuera de la clase alta viajaba a ninguna parte por razones que no fueran trabajo y negocios. Y esta es la característica central del turismo masivo en las sociedades modernas, a saber que muchas personas en todos los años viajarán a algún lugar para contemplarlo y permanecer ahí básicamente por razones ajenas al trabajo. Se estima que viajar ocupa el 40 por ciento del 'tiempo libre' disponible en Gran Bretaña (Williams y Shaw, 1988b: 12). Si la gente no viaja pierde status: el viajar es un símbolo de status. Es un elemento crucial de la vida moderna sentir que el viajar y las vacaciones son necesarios. 'Necesito vacaciones' es la más segura afirmación de un discurso moderno basado en la idea de que la salud física y mental de la gente se recuperará si tan solo pueden 'irse' de tiempo en tiempo.

La importancia de esto se puede ver en la mera escala del viaje contemporáneo. Hay 698 millones de llegadas de pasajeros internacionales cada año, comparado con los $25 \mathrm{mi}-$ llones de 1950 - con la predicción de que el total para el 2010 será de mil millones y para el 2020 será de mil seiscientos millones. Hubo un aumento de 7.4 por ciento en los viajes en 2000 solamente (WTO, 2000a). En cualquier momento hay 300,000 pasajeros en vuelo sobre los EEUU, el equivalente a una ciudad importante. Hay dos millones de pasajeros aereos diarios en EEUU (Gottdiener, 2001: 1). Se construye medio millón de habitaciones de hotel anualmente, mientras que hay 31 millones de refugiados en el planeta (Kaplan, 1996: 101; Makimoto y Manners, 1997: Cap. 1; Papastergiadis, 2000: 
Cap. 2). El turismo mundial está creciendo entre 4 y 5 por ciento por año. 'Los viajes y el turismo' son la industria más grande del mundo, siendo el 11.7 por ciento del $\mathrm{PBI}$ mundial, 8 por ciento de las exportaciones mundiales y 8 por ciento de todo el empleo (WTTC, 2000: 8; sitio web de Tourism Concern).

Esto ocurre casi en todas partes, con la Organización Mundial del Turismo publicando estadísticas de turismo/viajes de más de 180 paises con por lo menos 70 paises recibiendo más de un millón de llegadas internacionales de turistas al año (WTO, 2000a ; 2000b). Casi no hay pais en el mundo que no sea un receptor significativo de visitantes. Sin embargo, el flujo de estos turistas se origina de manera muy desigual, con los 45 paises que tienen un desarrollo humano más 'alto' siendo los que originan las tres cuartas partes de las salidas del turismo internacional (UNDP, 1999: 53-5). Esta movilidad es enormemente costosa para el ambiente con el transporte siendo responsable de alrededor de un tercio de las emisiones de $\mathrm{CO} 2$ (ver las muchas cuentas de Tourism in Focus). Asombrosamente se predice que mundialmente el viajar en automóvil se triplicará entre 19902050 (Hawkin, Lovins, 1999).

En el Reino Unido los servicios relacionados al turismo actualmente emplean alrededor de 1.8 millones de personas: tal empleo habiendo aumentado en un 40 por ciento desde 1980 mientras que el empleo en general ha aumentado solo marginalmente (sitio web del Dept Of Culture, Media and Sport). EI gasto de los turistas extranjeros en el Reino Unido es actualmente de 13 mil millones de libras esterlinas (sitio web del Dept Of Culture, Media and Sport). Estas cifras reflejan las muchas nuevas locaciones turísticas que se han abierto en las últimas dos o tres décadas. Hubieron 800 atracciones para visitantes en 1960, 2,300 en 1983 y 6,100 en 2000 (Cabinet Office, 1983; sitio web del Dept Of Culture, Media and Sport; Hanna, 2000). En 1987, se hicieron 233 millones de visitas a estas atracciones; para 1998 la cifra aumento a $395 \mathrm{mi}-$ llones (The Guardian diciembre 12, 1988; sitio web del Dept Of Culture, Media and Sport). Aparte del Domo del Milenio ( con 6.5 millones de visitantes en 2000), las locaciones más importantes en la Gran Bretaña son Blackpool Pleasure Beach (7.2 millones de visitantes), Tate Modern ( 5 millones de visitantes), Alton Towers (2.7 millones de visitantes), Madame Tussauds (2.6 millones de visitantes) y la Torre de Londres (2.4 millones de visitantes) (English Tourism Council, 2000/2001). Sin embargo, la proliferación de nuevas locaciones ha significado que muchas luchan por atraer suficientes visitantes pagantes y ha habido algunos cierres en atracciones recientemente abiertas (Hanna, 2000: A79-88).

Ha habido un aumento significativo en viajes personales. Entre 1970 y fines de los noventas ha habido un incremento del 50 por ciento en el millaje total de pasajeros domésticos en Gran Bretaña; 6,728 millas son viajadas cada año (www.transtat.detr.gov.uk). Aun para 1985 , el 70 por ciento de la gente vivia en hogares que poseía un auto, mientras que ahora la cuarta parte de los hogares posee dos autos.

El poseer un auto ha permitido un incremento en el número de vacaciones domésticas en Gran Bretaña, lo que aumentó de $126 \mathrm{mi}$ llones en 1985 a 146 millones en 1999, a pesar de que consistían mayormente de vacaciones cortas o medianas (Key Note Report, 1987: 15; English Tourism Council, 2000/2001). Ha habido un muy significativo incremento en las visitas a amigos y parientes; esto creció más aceleradamente en los noventas que cualquier otra forma de turismo doméstico especialmente entre la juventud. Los viajes de negocios representan un octavo de todos los viajes (English Tourism Council, 2000: F7-14).

Al mismo tiempo ha habido un marcado incremento en el número de vacaciones en el extranjero. In 1976 alrededor de 11.5 millones de visitas fueron hechas en el extranjero por residentes del Reino Unido. Para 198628 por ciento de los británicos se fueron al extranjero, realizando alrededor de 25 millones de viajes, de los cuales alrededor de la cuarta parte fueron a España (Mitchinson, 1988: 48; Business Monitor Quarterly Statistics, MQ6 Overseas Travel and Tourism). $Y$ para 1998, los ciudadanos del Reino Unido hicieron 51 millones de visitas el extranjero (BTA 2000: 52-3). 
Ha habido un incremento en el número de turistas que ingresan al Reino Unido. Hubieron 11 millones de visitas en 1976, 15.5 millones en 1987 y 25 millones en 1999 (Landry et al., 1989: 45; sitio web de la British Tourist Authority). El Reino Unido es el sexto destino más visitado, después de Francia, EEUU, España, Italia y China, solo un poco mejor que la Federación Rusa, Canada y Mexico (sitio web de la World Tourism Organization; el Reino Unido es quinto en término de recibos).

Finalmente, el gasto de estos visitantes implica el cinco por ciento del mercado del ocio, buena parte de dicho gasto estando dirigido a desembolso al por menor. (Martin y Mason, 1987: 95-6). Los turistas locales gastan en menor proporción en compras pero aun aqui la proporción está en aumento. Martin y Mason concluyen: 'comprar se está haciendo más significativo al turista, como un área de gasto y como incentivo para viajar' (1987: 96). En 1998/9 el desembolso por hogar en transporte había alcanzado el 17 por ciento del desembolso total, aumentando de alrededor de 14 por ciento de diez años antes ( sitio web del Department of the Environment, Transport and the Regions/Transport Statistics).

En la siguiente sección brevemente considero algunas de las principales contribuciones teóricas que han intentado encontrar un sentido sociológico para estos extensos flujos humanos.

\section{Enfoques teóricos del estudio del turismo}

Está visto que encontrar el sentido teórico de 'diversión, placer y entretenimiento' es una tarea difícil para los científicos sociales. En esta sección resumiré algunas de las principales contribuciones a la sociología del turismo. No carecen de interés pero todavía hay mucho trabajo por hacer. En el resto del artículo desarroIlo algunas nociones relevantes al entendimiento teórico de la actividad turística, sacando provecho de contribuciones acá analizadas y conectando el desarrollo a debates sobre la emergente 'globalización'.

Una de las formulaciones más tempranas es el análisis de Boorstin sobre el 'seudo- evento' (1964; y ver Cohen, 1988). El indica, en parte anticipándose a Baudrillard, que los norteamericanos contemporáneos no pueden experimentar 'la realidad' de manera directa sino que prosperan en los 'seudo-eventos'. El turismo es un excelente ejemplo de estos (ver Eco, 1986; Baudrillard, 1988). Aislado del entorno original y de la gente local, el turista masivo viaja en grupos guiados y encuentra placer en atracciones ideadas de manera inauténtica, ingenuamente disfrutando 'seudo-eventos' y despreciando el mundo 'real' de afuera. Como resultado los empresarios del turismo y las poblaciones locales se ven inducidos a producir exhibiciones cada vez más extravagantes para el observador incauto que entonces es alejado aun más de la gente local. En el tiempo, por medio de la publicidad y los medios de comunicación, las imágenes generadas de diferentes contemplaciones turísticas se constituyen en un sistema de ilusiones cerrado que se auto-perpetúa dando al turista una base para seleccionar y evaluar locaciones potenciales para visitar. Estas visitas se realizan, según Boorstin, dentro del 'entorno burbuja' del hotel familiar de estilo norteamericano que aisla al turista de lo extraño del entorno anfitrión.

Un buen número de escritores posteriores desarrolla y refina esta relativamente simpe tésis de un desplazamiento histórico del 'viajero individual' al 'turista de la sociedad de masas'. Particularmente interesante es Las Hordas Doradas de Turner y Ash (1975), que desentraña la teoría de cómo el turista es colocado en el centro de un mundo estrictamente circunscrito. Padres sustitutos (agentes viajeros, correos, gerentes de hoteles) alivian al turista de la responsabilidades y lo protegen de la dura realidad. Sus atenciones restringen al turista a la playa y ciertos objetos aprobados de la contemplación turística (ver Edensor 1998, sobre creadores de paquetes vacacionales en el Taj Mahal). De alguna forma, Turner y Ash sugieren, la sensualidad y sentido estético del turista están tan restringidos como lo están en su país natal. Ello se se acentúa aun más debido a la forma relativamente superficial en que las culturas locales deben ser presentadas al turista. Dicen sobre Bali que: 'Muchos aspectos de la cultura y el arte balineses son tan desconcertantemente complejos y extraños a los modos occidentales que no se prestan fácilmente para 
el proceso de sobre simplificación y producción masiva que convierte las formas nativas de arte en kitsch turístico' (Turner y Ash, 1975: 159; Bruner, 1995).

La conclusión es que en la búsqueda de lugares siempre nuevos para visitar, lo que se construye es un conjunto de hoteles y vistas turisticas que es blanda y carente de contradicciones, ' un pequeño mundo monótono que en todas partes nos muestra nuestra propia imagen ... la búsqueda de lo exótico y diversos fines en la uniformidad' (Turner y Ash, 1975: 292).

Cohen crítica en algo esta tradición pues dice que no hay un solo turista como tal sino una variedad de tipos de turistas o modos de experiencia turistica (ver 1972, 1979, 1988, de varias formulaciones principalmente extraídas de la sociología de la religión). Lo que el denomina lo 'experiencial', lo 'experimental' y lo 'existencial' no se basa en la burbuja ambiental de los servicios turísticos convencionales. En diversos grados estas experiencias turísticas se basan en rechazar estas formas de organizar la actividad turística. Más aun, uno debería notar que la existencia de dichas burbujas permite que mucha gente visite lugares que de otra manera no visitarían y que por lo menos tengan algo de contacto con los lugares 'extraños' asi encontrados. Es más, hasta que estos lugares hayan desarrollado una infraestructura turística completa muchas de las 'rarezas' de estos destinos serán imposibles de esconder o de empaquetar dentro de un abanico completo de 'seudo-eventos'.

El reto más importante a la posición de Boorstin es el de MacCannell, quien también está preocupado con la inautenticidad y superficialidad de la vida moderna (1999; orig. 1976). El cita a Simmel en torno a la naturaleza de las impresiones sensoriales experimentadas en la 'metrópolis': 'el rápido acumulamiento de imágenes cambiantes, la aguda discontinuidad en el alcance de una sola mirada y lo inesperado de las impresiones que fluyen sin fin' (MacCannell, 1999: 49). El afirma que esto es sintomático de la experiencia turística. El está en desacuerdo con el relato de Boorstin al que considera como un reflejo característico del punto de vista de la clase alta que 'otros son tu- ristas, mientras yo soy un viajero' (1999: 107; y ver Buzard 1993, sobre esta distinción). Para MacCannell todos los turistas revisten una búsqueda de la autenticidad y esta búsqueda es una versión moderna de la preocupación humana sobre lo sagrado.

El turista es una especie de peregrino contemporáneo, buscando la autenticidad en otros 'tiempos' y otros 'lugares' lejos de la vida diaria de esa persona. Los turistas tienen una especial fascinación por la 'vida real' de otros quienes de alguna manera poseen una realidad difícil de descubrir en sus propias experiencias. La sociedad moderna, por lo tanto, está institucionalizando los derechos de los foráneos a escudriñar sus quehaceres. 'Las instituciones están provista de coliseos, plataformas y compartimentos reservados para el uso exclusivo de los turistas' (MacCannell, 1999: 49). Casi todo tipo de trabajo, aun el quebradero de espalda de trabajo que tiene un minero galés o el nada envidiable quehacer de quienes laboran en los desagües de París, puede ser objeto de la contemplación del turista.

MacCannell esta particularmente interesado en el carácter de las relaciones sociales que emergen de esta fascinación que la gente tiene especialmente en la vida laboral de otros. Anota que estas 'vidas reales' solo pueden ser encontradas en bambalinas y no se nos hacen evidentes de manera inmediata. Por ello, la contemplación del turista implicará una obvia intrusión en la vida de la gente, lo que generalmente será inaceptable. Entonces, los observados y los empresarios turísticos locales gradualmente empiezan a tramar la creación de bambalinas de manera artificial. 'Los espacios turísticos' se organizan por tanto en torno a lo que MacCannell llama 'autenticidad escenificada' (1973). El desarrollo de la atracción turística construida resulta de cómo aquellos que son sujeto de la contemplación turística responden, tanto para protegerse de las intrusiones en sus vidad en bambalinas como para tomar ventaja de las oportunidades que ello representa para las inversiones lucrativas. En contraste con Boorstin, MacCannell arguye que los 'seudoeventos' son la resultante de las relaciones sociales del turismo y no de una búsqueda individualísta de lo inauténtico. 
Pearce y Moscardo han desarrollado aun más la noción de la autenticidad (1986; y ver la crítica en Turner y Manning, 1988). Ellos sostienen que es necesario distinguir entre la autenticidad de la locación y la autenticidad de las personas contempladas; y para distinguir entre los diversos elementos de la experiencia turística que son importantes para el turista en cuestión. Crick, por contraste, indica que hay un sentido en el cual todas las culturas son 'puestas en escena' e inauténticas. Las culturas son inventadas, rehechas y los elementos reorganizados (Crick, 1988: 65-6). Por lo tanto, no está claro por que el aparente inauténtico montaje para el turista es muy distinto de los procesos de refacción cultural que ocurren en todas las culturas de todas maneras (ver Rojek y Urry, 1997). Basado en investigaciones llevadas a cabo en New Salem, donde Abraham Lincoln pasó algunos años de la década de 1830 , Bruner distinguió varios sentidos conflictivos de lo auténtico (1994; y ver Wang, 2000). Primero, existe lo auténtico en el sentido de un pequeño pueblo que parece que ha adquirido la antigüedad adecuada a lo largo de los últimos 170 años, sean las construcciones realmente asi de antiguas 0 no. Segundo, esta el pueblo que se ve como se debió ver en la década de 1830 , es decir, mayormente compuesto de edificaciones nuevas. Tercero, están las construcciones y los artefactos que literalmente son de la década de 1830 y que están ahi desde ese entonces. Y cuarto, están las construcciones y artefactos que han sido autorizados como auténticos por el fideicomiso que supervisdala 'herencia' dentro del pueblo. Holderness (1988) también ha descrito los procesos en Stratford-upon-Avon por el cual el fideicomiso del natalicio de Shakespeare ha venido a ejercer un papel hegemónico en el pueblo, determinando que edificaciones, lugares y artefactos son auténticamente parte de la 'herencia de Shakespeare' y cuales no son tan 'auténticos' (ver Lash y Urry, 1994: 264-6). Bruner también anota que New Salem ahora es totalmente distinto de la década de 1830 ya que en el período antecedente no habrían habido turistas saludando a las cámaras y paseándose en grandes números viendo emocionados a los actores vestidos como si fueran residentes de una época previa y hace tiempo desaparecida.

MacCannell también observa que, a diferencia del peregrino religioso que rinde un homenaje a un centro sagrado único, el turista rinde homenaje a un gran abanico de centros de atracción. Esto incluye locaciones industriales y laborales. Esto es por que el trabajo se ha convertido en un mero atributo de la sociedad y no es su característica principal (MacCannell, 1999: 58). MacCannell indica que este interés en los despliegues laborales es un 'placer alienado'. Es una perversión del objetivo del placer ya que involucra un retorno paradójico al centro de trabajo.

También anota que cada centro de atracción involucra complejos procesos de producción para que las contemplaciones turísticas normales, significativas y lucrativas puedan ser generadas y sean sostenibles. Tales contemplaciones no pueden ser dejadas al azar. La gente debe aprender cómo, cuándo y dónde 'contemplar'. Se deben proveer hitos claros y en algunos casos el objeto de la contemplación es tan solo el hito que indica algún evento o experiencia que previamente ocurrió en dicho lugar.

MacCannell sostiene que hay normalmente un proceso de sacralización que convierte a un artefacto natural o cultural en particular en objeto sagrado del ritual turístico (1999: 42-8). Un número de etapas está involucrado en esto: dar un nombre a la locación, encuadre y elevación, enclaustamiento, reproducción mecánica del objeto sagrado y la reproducción social cuando otros lugares (o 'locaciones') se nominalizan con el nombre de la famosa. Es también importante anotar que no solamente hay muchas atracciones a las cuales rendir culto, sino que muchas atracciones son contempladas por solo una vez. En otras palabras, la contemplación del turista puede ser tremendamente veleidosa, buscando o anticipando algo nuevo o algo diferente. MacCannell anota que 'cualquier cosa es potencialmente una atracción. Simplemente espera a que una persona la mencione a otra como algo que vale la pena o que vale la pena ver' (1999: 192).

El complejo proceso involucrado en esto es parcialmente revelado en el análisis de Turner del peregrinaje $(1973 ; 1974)$. Importantes ritos de pasaje envuelven el movimiento de una etapa a otra. Son tres estas etapas: primero, la separación social y espacial del lugar normal de residencia y de los lazos sociales 
convencionales; segundo, liminalidad, cuando la persona se encuentra en una 'anti-estructura' ... fuera de tiempo y lugar' - las ataduras sociales convencionales están suspendidas, se experimenta intensos lazos 'communitas' y hay una directa experiencia de lo sagrado o sobrenatural; y tercero, reintegración, donde el individuo es reintegrado con el grupo social previo, normalmente en un status más alto.

Aunque este análisis se aplica a los peregrinos, otros escritores llegan a estas conclusiones para los turistas (ver Cohen, 1988: 3840; Shields, 1990; Eade y Sallnow 1991). Como el peregrino el turista se mueve de un lugar familiar a un lugar distante y luego retorna al lugar familiar. En el lugar distante tanto el peregrino como el turista se involucran en 'adorar' los santuarios que son sagrados, aunque de diferente manera, y como resultado ganan una experiencia enaltecedora. En el caso del turista Turner y Turner hablan de situaciones 'liminoides' (1978). Lo que se indica acá es algo que no profundiza MacCannell, a saber que en mucho turismo las obligaciones cotidianas están suspendidas o invertidas. Hay una licencia para la conducta 'no seria' permisiva y juguetona y se alienta una relativamente no forzada 'communitas' o acercamiento social. Tales argumentos hacen cuestionar la idea de que solo hay 'rutina' - acción habitual, como arguye por ejemplo Giddens (1984). Lo que frecuentemente está involucrado es una acción semi rutinaria o una especie de rutina de la no rutina.

Un análisis de esto es la exploración de Shields de la 'capital mundial de la luna de miel', Niagara Falls (1990). El ir a Niagara de luna de miel efectivamente implicó un peregrinaje, se entró en una experiencia de liminalidad en la que los códigos de la experiencia social normal se invertían. En particular aquellos de luna de miel se encontraban históricamente en una zona liminal ideal donde las estrictas convenciones sociales de la familia burguesa se relajaban bajo las exigencias del viaje de un relativo anonimato y libertad para el escrutinio colectivo. En una novela escrita en 1808 un personaje dice de Niagara: 'En otras partes se preocupan por los negocios y la moda, existe la edad, la pena y las penas del corazón; pero aquí solo hay juventud, fe, éxtasis' (cita Shields, 1990).
Shields también plantea como Niagara, como Gretna Green en Escocia, se ha convertido en un signo carente de contenido, un cliché comercial completo.

Algunos escritores en esta línea argumentan que tal comportamiento juguetón o 'lúdi$\mathrm{Co}^{\prime}$ es priariamente restitutivo o compensatorio, revitalizando al turista para su retorno a lugar familiar del hogar y el trabajo (ver Lett, 1983 sobre turismo lúdico en yate). Otros escritores, por contraste, adoptan una interpretación menos funcional e indican que las nociones generales de liminalidad e inversión deben recibir un contenido más preciso. Es necesario investigar la naturaleza de los patrones sociales y culturales dentro de la existencia día-a-día del turista para ver que está invertido y cómo la experiencia liminal se desarrollará. Gottlieb argumenta, por ejemplo, que lo que se busca en una vacación es la inversión de lo cotidiano. El turista de clase media querrá ser 'rey/reina por un día' (ver Gottlieb, 1982). Anque estos son ejemplos poco convincentes, si apuntan a una característica crucial del turismo, a saber que típicamente hay una clara distinción entre lo familiar y lo lejano y que tales diferencias producen distintas clases de zonas liminales.

Por lo tanto parece incorrecto sugerir que tal búsqueda de la autenticidad es la base de la organización del turismo. Más bien, una característica fundamental pareceria ser que hay diferencias entre el lugar normal de residencia y trabajo de uno y el objeto de la contemplación turística. Ahora bien, puede ser que la búsqueda de lo que consideramos elementos auténticos sea un componente importante acá, pero esto es solo porque hay, de alguna manera, un contraste con las experiencias cotidianas. Más aun, recientemente se ha argumentado que algunos visitantes -lo que Feifer (1985) llama 'post-turistas'- casi se deleitan en la inautenticidad de la experiencia turística normal. Los 'post-turistas' encuentran placer en la multiplicidad de los juegos turísticos. Saben que no hay una auténtica experiencia turistica, que solo hay una serie de juegos o textos que se pueden jugar. En los siguientes capítulos encuentro algunas importantes conecciones entre la noción del post-turista y el más amplio desarrollo cultural del postmodernismo. 
Por el momento sin embargo, es necesario considerar simplemente qué es lo que produce una contemplación turistica específica. Minimamente deben existir ciertos aspectos del lugar a ser visitado que lo distinguen de lo que normalmente se encuentra en la vida cotidiana. El turismo resulta de una división binaria básica entre lo ordinario/cotidiano y lo extraordinario. Las experiencias turisticas implican algún elemento $o$ aspecto que induce experiencias placenteras que, en comparación con la vida cotidiana, son fuera de lo común (ver Robinson, 1976: 157). Esto no quiere decir que otros elementos de la producción de la experiencia turistica no harán que un típico turista sienta que el o ella está 'en casa fuera de casa', no tan 'fuera de lugar'. Pero los potenciales objetos de la contemplación turística deben ser diferentes de alguna manera u otra. Debe estar fuera de to común. La gente debe experimentar placeres particularmente diferenciados que involucren diferentes sentidos o son de una escala diferente a la de aquellos típicamente hallados en la vida cotidiana. Hay, sin embargo, muchas diferentes maneras en las que tal división entre lo ordinario y lo extraordinario es establecido $y$ mantenido.

Primero, esta el ver un objeto único, como la Torre Eiffel, el Edificio Empire State, el Palacio de Buckingham, el Gran Cañón, o aun el lugar mismo en Dallas donde le dispararon al presidente Kennedy (ver Rojek, 1990 sobre lo último). Hay objetos absolutamente diferentes para ser contemplados, que son conocidos por todos. Son famosos por ser famosos, aunque estos lugares pueden haber perdido la razón por la cual son famosos (tal como el Edificio Empire State, que aun atrae dos millones de personas al año). La mayoria de la gente que vive en 'occidente' desearia ver algunos de estos objetos durante su vida. Implican una especie de peregrinaje a un centro sagrado que frecuentemente es una ciudad capital, una gran ciudad o la locación de un mega-evento único (ver Roche, 2000).

Luego está el ver señas particulares como el pueblo inglés típico, el típico rascacielos americano, el típico salón de cerveza alemán, el típico castillo francés y así sucesivamente. Este modo de contemplar muestra como de alguna manera los turistas son semiotas, leyendo el panorama por significantes de ciertas pre establecida nociones o signos derivados de varios discursos de viajes y turismo (ver Culler, 1981: 128).

Tercero, esta es ver aspectos desconocidos de lo que previamente se había creído que era familiar. Un ejemplo es el visitar museos que muestran representaciones de vidas de gente común, revelando especialmente sus artefactos culturales. Frecuentemente esto se muestran en un ambiente 'realista' para mostrar cómo eran sus casas, centros de trabajo y fábricas. Los visitantes ven objetos desconocidos de la vida de otras personas que se presumían familiares (ver Urry, 1996, sobre reminiscencias del pasado).

Luego tenemos el ver los aspectos ordinarios de la vida social presentados por personas en contextos inusuales. Algo del turismo en China ha sido de este tipo. A los visitantes les ha parecido especialmente interesante contemplar el desarrollo de las tareas domésticas en un país 'comunista' y, así, ver como las rutinas de la vida son sorprendentemente no tan poco familiares.

También está el desarrollar tareas familiares o actividades dentro de un entorno visual inusual. La natación y otros deportes, ir de compras, comer y tomar, todos tienen una particular significancia si se llevan a cabo contra un telón de fondo visual distintivo. La contemplación visual hace extraordinarias a actividades que de otra manera serían mundanas y de todos los días.

Finalmente, está el ver señas particulares que indican que cierto otro objeto es en realidad extraordinario, aun cuando no parezca serlo. Un buen ejemplo de tal objeto es la piedra lunar que no parece nada especial. La atracción no está en el objeto en si sino el signo al que se refiere que lo marca como distintivo. Asi el hito se convierte en la locación distintiva (Culler, 1981: 139). Una mirada similar se da en las galerías de arte cuando parte de lo que es contemplado es el nombre del artista, 'Rembrandt dice tanto como la pintura misma, que será difícil de distinguir de muchas otras en la misma galeria.

He argumentado que el carácter de la mirada es central al turismo. Campbell, sin 
embargo, hace una importante acotación relacionado más genéricamente al carácer del consumo como tal (1987). El dice que el ensueño y la anticipación escondidos son procesos centrales para el moderno consumismo. Los individuos no buscan satisfacción en los productos por la selección, compra y uso de los mismos. Más bien la satisfacción deviene de la anticipación, de la búsqueda imaginativa del placer. Por lo tanto, la motivación para el consumismo de la gente no es meramente materialista. Es más bien que buscan experimentar 'en la realidad' los dramas apetecibles que ya han experimentado en su imaginación. Sin embargo, como la 'realidad' rara vez provee de placeres perfecos hallados en el ensueño, cada compra conduce a la desilusión y al deseo de productos siempre más nuevos. Hay una dialéctica entre novedad e insaciabilidad en el corazón del moderno consumismo.

Campbell parece visualizar el 'hedonismo imaginativo' como una característica relativamente autónoma de las sociedades modernas y separada de arreglos institucionales específicos, tales como la publicidad, o de modos particulares de emulación social (1987: 88-95). Es 'difícil encarar la naturaleza del turismo contemporáneo sin ver cómo estas actividades son literalmente construídas en nuestra imaginación por medio de la publicidad y los medios de comunicación y por la competencia consciente entre diferentes grupos sociales' (ver Selwyn, 1996, sobre imágenes del turismo). Si Campbell está en lo cierto al decir que el consumismo contemporáneo involucra la búsqueda imaginativa del placer, entonces el turismo es el caso paradigmático. El turismo necesariamente involucra el ensueño y la anticipaciónde experiencias nuevas o diferentes de aquellas normalmente encontradas en la vida cotidiana. Pero esta ensoñación no es autónoma; involucra trabajar con publicidad y juegos de signos creado por medios de comunicación, muchos de los cuales se relacionan claramente con procesos complejos de emulación social.otro problema en el análisis, por otro lado útil, de Campbell es que el trata al consumismo moderno como si fuera históricamente fijo. Así, falla al referirse al carácter cambiante del consumismo y las posible transformaciones paralelas en la naturaleza de la producción capitalista (el consumo es usado aqui enel sentido de 'compra' y no implica la ausencia de producción al interior de los hogares).Muchos escritores argumentan ahora que un gran cambio se está dando en las sociedades contemporáneas, al producirse un vuelco del capitalismo organizado al desorganizado (ver Lash y Urry, 1987, 1994). Otros escritores se refieren a un movimiento del Fordismo al post Fordismo y en particular indican que hay un giro del consumo masivo a patrones de consumo más individualizados (ver Aglietta, 1987; Hirschhorn, 1984; Piore y Sabel, 1984; Poon, 1993).

Pero este lado del análisis en torno al consumismo no ha sido desarrollado, permitiendo ver la parcialidad 'productivista' en mucha de la literatura. Ahora planteo dos tipos ideales de consumo masivo Fordista y de consumo diferenciado post Fordista.

Consumo masivo: la adquisición de comodidades producidas bajo condiciones de producción masiva; una tasa mayor y creciente de gasto en productos de consumo; productores individuales tendiendo a dominar mercados industriales específicos; el productor antes que el consumidor como dominante en el mercado; las comodidades poco diferenciadas una de otra por moda, estaciones y segmentos específicos del mercado; relativamente pocas opciones - lo que hay tiende a reflejar los intereses del productor sea privado o público.

Consumo post Fordista: el consumo antes que la producción es el dominante por que el gasto del consumidor sigue incrementándose como una parte del ingreso nacional; nuevas formas de crédito permiten que el gasto del consumidor aumente, produciendo así altos niveles de deuda; casi todos los aspectos de la vida social se comodifican, aun las caridades; mayor diferenciación de los patrones de compra por segmentos de mercado diferenciados; mayor volatilidad de las preferencias de los consumidores; el crecimiento de un movimiento de consumidores y la 'politización' del consumo; reacción de los consumidores contra el ser parte de la 'masa' y la necesidad de los productores de estar mucho más orientados hacia el consumidor, especialmente en el caso de las industrias de servicios y las de propiedad pública; el desa- 
rrollo de muchos más productos cada uno de los cuales tiene una vida más corta; la emergencia de nuevos tipos de comodidades que están más especializadas y basadas en materias primas que implican formas no masivas de producción (productos 'naturales' por ejemplo).

De hecho hay muchos modos de consumo que implican cortes transversales de esta división. Sin embargo, hay evidencia considerable de que las sociedades occidentales se han estado movimiento en términos gruesos del primer tipo al segundo. Si esto es así entonces este giro también se reflejará en el carácter cambiante del turismo contemporáneo. (ver Poon, 1993; Urry, 1995a). En Inglaterra el campamento vacacional era la quintesencia del ejemplo de cómo se hacía las vacaciones en el estilo Fordista. Al trasladarse al post-Fordismo tales campamentos han sido renombrados 'centros' o 'mundos de vacaciones' y ahora se pre- sentan como lugares de 'libertad'. Demuestro en los siguientes capítulos que muchos otros cambios ocurren en la manera contemporánea de hacer vacaciones dentro de un estilo más o menos 'post-Fordista'. Poon (1993) ha puesto de manifiesto que estos cambios involucran un giro del 'viejo turismo', que implicaba empaquetar y estandardizar, al 'nuevo turismo' que es segementado, flexible y hecho a pedido. El director de mercadeo de British Airways escribió ya en la década de 1980 sobre 'el fin del mercado de masas en el negocio de los viajes... vamos a ser mucho más sofisticados en la manera que segmentamos nuestro mercado' (cita Poon, 1989: 94).

\author{
John Urry \\ Departamento de Sociología \\ Universidad de Lancaster \\ Inglaterra
}




\section{Bibliografía}

ADLER, J.

1989 "Origins of Sightseeing, Annals of Tou -rism Research, 16: 7-29.

AGLIETTA, $M$.

1987 A Theory of Capitalist Regulation: the US Experience, Verso, London.

BAUDRILLARD, J.

1988 America, Verso, London.

BOORSTIN, D.

1964 The Image: A Guide to Pseudo-Events in America, Harper, New York.

BRUNER, E.

1994 "Abraham Lincoln as authentic repro duction: a critique of postmodernist", American Anthropologist, 96: 397-415

BRUNER, E.

1995 Holiday Making and the Holiday Trades. Oxford University Press, Oxford

BTA

2000 Digest of Tourism Statistics. $N^{\circ} 23$, British Tourism Authority, London

BUZARD, J.

1993 The Beaten Track, Clarendon Press, Oxford.

CABINET OFFICE (Enterprise Unit)

1983 Pleasure, Leisure and Jobs. The Business of Tourism. HMSO, London

CAMPBELL, C.

1987 The Romantic Ethic and the Spirit of Modern Consumerism, Basil Blackwell, Oxford

CLARK, P.

1983 The English Alehouse: a Social History, 1200-1830, Longman, London.
COHEN, E.

1972 "Towards a sociology of international tourism" Social Research, 39: 164-82

COHEN, E

1979 "A phenomenology of tourist types" Sociology, 13: 179-201

COHEN, E.

1988 "Traditions in the qualitative sociology of tourism", Annals of Tourism Research. Special Issue, 15: 29-46

CRICK, M.

1988 "Sun, sex, sights, savings and servility", Criticim, Heresy and Interpretation, 1: 37-76

CULLER, J.

1981 "Semiotics of Tourism" American Journal of Semiotics, 1: 127-40

DENT, K.

1975 "Travel as education: the English landed classes in the eighteenth century", Educational Studies, 1: 171-80

EADE, J. y SALLNOW, M.

1991 Contesting the Sacred. The Anthropology of Christian Pilgrimage, Routledge, London.

ECO, U.

1986 Travels in Hyper-Reality, Picador, London.

EDENSOR, T.

1998 Tourist at the Taj, Routledge, London

ENGLISH TOURISIM COUNCIL

2000/2001 ETC Insights, London, ETC

FEIFER, M.

1985 Going Places, Macmillan, London.

FOUCAULT, M.

1976 The Birth of the Clinic, Tavistock, London 


\section{GIDDENS, A.}

1984 The Constitution of Society, Polity, Cambridge

\section{GOTTDIENER, M.}

2001 Life in the Air. Surviving the New Culture of Air Travel, Rowman and Littlefield, Lanham, Mass.

GOTTLIEB, A.

1982 "Americans" vacations", Annals of tourism Research, 9: 165-87.

HANNA, M.

2000 "Sightseeing Trends in 1999" ETC Highlights, English Tourism Council, London.

HARRISON, B

1971 Drink and the Victorians, Faber \& Faber, London.

HAWKINS, P., LOVINS, A. , Lovins, L.H.

1999 Natural Capitalism, Earthscan, London.

HIRSCHHORN, L.

1984 Beyond Mechanization, MIT Press, Cambridge, MA.

HOLDERNESS, G.

1988 "Bardolatry: or, the cultural materialist's guide to Stratford-upon-Avon", in G. Holderness (ed.) The Shakespeare Myth, Manchester University Press, Manchester.

KAPLAN, C.

1996 Questions of Travel, Duke University Press, Durham.

\section{KEY NOTE REPORT}

1987 Tourism in the UK, Key Note Publications, London.

LANDRY,C. MONTGOMERY, j. WORPOLE, K., GRATTON,C. AND MURRAY, R.

1989 The Last Resort, Comedia Consultancy/ SEEDS (South East Economic Development Strategy), London.
LASH, S and URRY, J.

1987 The End of Organized Capitalism, Polity, Cambridge.

LASH, S. and URRY, J.

1994 Economies of Signs and Space, Sage, London.

LETT, J.

1983 "Ludic and liminoid aspects of charter yatch tourism in the Caribbean", Annals of Tourism Research, 10: 35-36.

MacCANNELL, D.

1973 "Staged authenticity: arrangements of social space in tourist settings", American Sociological Review, 79: 589-603.

MacCANNELL, D.

1999 The Tourist, Schocken, New York, (orig. 1976).

MAKIMOTO, T. and MANNERS,D.

1997 Digital Nomad. John Wiley, Chichester.

MARTIN, B. and MANSON, S.

1987 "Current trends in leisure", Leisure Studies, 6: 93-7

MITCHINSON, A.

1988 "New Society database. Holidays", New Society, 22 April.

MYERCOUGH, J.

1974 "The recent history of the use of leisure time" in I. Appletton (ed.) Leisure Research and Policy, Scottish academic Press, pp. 3-16, Edinburgh.

PAPASTERGIADIS, $\mathrm{N}$.

2000 The Turbulence of Migration, Polity, Cambridge.

PEARCE,P and MOSCARDO,G

1986 "The concept of authenticity in tourist experiences", Australian and New Zealand Journal of Sociology, 22: 121-32. 
PIORE,M. and SABEL, C.

1984 The Second Industrial Divide, Basic Books, New York.

POON, A

1989 "Competitive strategies for a "new tourism" ", in C. Cooper (ed) Progress in tourist, Recreation and Hospitality Management Vol. 1., Belhaven Press, pp. 91-102, London

POON, A.

1993 Tourist, Technology and Competitive Strategies, CAB International, Wallingford, Oxon.

ROBINSON, $\mathrm{H}$

1976 A Geography of Tourism, Macdonald \& Evans, Plymouth.

ROCHE, M.

2000 Mega-Events and Modernity, Routledge, London.

ROJEK, C.

1990 Ways of Escape, Macmillan, London.

ROJEK, C and URRY, J.

1997 (eds.) Touring Cultures, Routledge, London

\section{SELWIN, T}

1996 (eds.) The Tourist Image, Wiley, Chichester.

SHIELDS, R.

1990 Places on the Margin, Routledge, London

THOMPSON, G.

1981 "Holidays", Unit 11 of popular Culture and Everyday Life (2), Milton Keynes, Open University Press.

TOWNER, J.

1985 "The Grand Tour: a key phase in the history of tourism", Annals of Tourism Research, 12: 297-33.
TOWNER, J.

1988 "Approaches to tourism history" Annals of Tourism Research, 15: 47-62.

TURNER, C and MANNING, P.

1988 "Placing authenticity- on being a tourist: a replay to Pearce and Meaning" Australian and New Zealand Journal of Sociology, 24: 136-8

TURNER, $\mathrm{L}$ and $\mathrm{ASH}, \mathrm{J}$.

1975 The Golden Hordes, Constable, London.

TURNER,V.

1973 "The center out there: pilgrim's goal", History of Religions, 12: 191-230.

TURNER, V.

1974 The Ritual Process, Penguin, Harmondsworth.

TURNER, V. and TURNER, E.

1978 Image and Pilgrimage in Christian Culture, Columbia University Press, New York.

UNDP

1999 Human Development Report, UNDP and Oxford University Press, New York.

URRY,J.

1995 Consuming Places, Routledge, London.

URRY, J.

1996 "How societies remember the past" in S. Macdonald and G. Fyfe (eds.) Theorizing Museums, Sociological Review Monographs and Blackwells,pp. 45-65, Oxford.

WANG, N.

2000 Tourism and Modernity, Elsevier, Oxford.

WILLIANS, A. and SHAW, G.

1988 "Western European tourism in perspec tive" in A. Williams and G. Shaw, G.(eds) Tourism and Economic Development, Belhaven Press, pp. 12-38, London. 
WTO

2000 Tourism Highlights 2000, world Tourism Organisation, Madrid.

WTO

2000 Yearbook of Tourism Statistics 2000, World Tourism Organisation, Madrid.
WTTC

2000

Summit for Economic Policymakers, World Travel and Tourism Council, Vol. $1, N^{\circ} 1$ 